\title{
Clinical outcome, role of BRAFV600E, and molecular pathways in papillary thyroid microcarcinoma: is it an indolent cancer or an early stage of papillary thyroid cancer?
}

\author{
Carmelo Nucera ${ }^{1}$ and Alfredo Pontecorvi ${ }^{2}$ \\ 1 Division of Cancer Biology and Angiogenesis, Harvard Medical School, Beth Israel Deaconess Medical Center, Boston, MA, USA \\ 2 Unit of Endocrinology, Department of Experimental Medicine, A. Gemelli Medical School, Catholic University, Roma, Italy
}

\section{Edited by:}

Martin Fassnacht, University Hospital

of Würzburg, Germany

Reviewed by:

Daniela Pasquali, Seconda Università degli Studi Napoli, Italy

Giancarlo Troncone, Univerdità di

Napoli Federico II, Italy

Michael C. Kreissl,

Universitätsklinikum Wuerzburg,

Germany

\section{*Correspondence:}

Carmelo Nucera, Division of Cancer Biology and Angiogenesis, Thyroid

Cancers Preclinical Research Models, Harvard Medical School, Beth Israel

Deaconess Medical Center, 99

Brookline Avenue, Room\#263,

Boston, MA, USA.

e-mail: cnucera@bidmc.harvard.edu
Most human thyroid cancers are differentiated papillary carcinomas (PTC). Papillary thyroid microcarcinomas (PTMC) are tumors that measure $1 \mathrm{~cm}$ or less. This class of small tumors has proven to be a very common clinical entity in endocrine diseases. PTMC may be present in $30-40 \%$ of human autopsies and is often identified incidentally in a thyroid removed for benign clinical nodules. Although PTMC usually has an excellent long-term prognosis, it can metastasize to neck lymph nodes; however deaths related to this type of thyroid tumor are very rare. Few data exist on molecular pathways that play a role in PTMC development; however, two molecules have been shown to be associated with aggressive PTMC. S100A4 (calcium-binding protein), which plays a role in angiogenesis, extracellular matrix remodeling, and tumor microenvironment, is over-expressed in metastatic PTMC. In addition, the BRAF ${ }^{\mathrm{V} 600 \mathrm{E}}$ mutation, the most common genetic alteration in PTC, is present in many PTMC with extra thyroidal extension and lymph node metastasis. Importantly, recently developed selective [e.g., PLX4720, PLX4032 (Vemurafenib, also called RG7204)] or non-selective (e.g., Sorafenib) inhibitors of BRAF ${ }^{\mathrm{V} 600 \mathrm{E}}$ may be an effective treatment for patients with BRAF ${ }^{V 600 E}$-expressing PTMCs with aggressive clinical-pathologic features. Here, we summarize the clinical outcome, cancer genetics, and molecular mechanisms of PTMC.

Keywords: papillary thyroid microcarcinoma, BRAF $^{1600 E}$ mutation, extracellular matrix, angiogenesis, tumor microenvironment, clinical outcome, genetics, neck lymph node metastasis

\section{INTRODUCTION}

The vast majority of human thyroid cancers are differentiated and pathological examination reveals that most of these are papillary thyroid cancers (PTC). The long-term prognosis and recommended treatment for patients with PTC are dependent on the stage of disease. Papillary thyroid microcarcinoma (PTMC) are small thyroid tumors ( $\leq 1 \mathrm{~cm}$ in diameter) that belong to the lowrisk well-differentiated PTC, which are probably of little clinical significance, and do not affect patient survival (Arem et al., 1999; Lloyd et al., 2004; Pazaitou-Panayiotou et al., 2007; Shaha et al., 2007). It is important to distinguish between PTMC in a clinically recognized malignant thyroid micro nodule and an incidental (asymptomatic) PTMC found after thyroidectomy performed for other indications (e.g., benign thyroid diseases) or during thyroid ultrasound. Incidental PTMC has an outstandingly good prognosis and there is nearly no risk of recurrence or death from PTMC (Sugitani and Fujimoto, 1999; Barbaro et al., 2005; McDougall and Camargo, 2007). However, PTMC may be associated with lymph node metastases at presentation and/or neck loco-regional recurrences during follow-up (Pazaitou-Panayiotou et al., 2007).

Papillary thyroid microcarcinomas may be categorized as: (i) PTMC found at autopsy or incidentally at histology, (ii) PTMC found incidentally during thyroid or neck ultrasound and diagnosed before surgery by cytology on thyroid fine needle aspiration (FNA) material, and (iii) clinical PTMC (i.e., tumors whose presenting symptoms were loco-regional or distant metastases). PTMCs are found in otherwise normal thyroids or in multinodular goiters (MNGs), and they account for nearly $50 \%$ of new cases of PTC (PTC accounts for over $80 \%$ of all human thyroid cancers; Leenhardt et al., 2004; Davies and Welch, 2006; Xing, 2009).

Papillary thyroid microcarcinomas are also referred to as small, tiny, or minute carcinomas. Some authors suggest that PTMC found at histology should be called "occult" papillary tumors instead of carcinomas to reflect their benignity.

The use of ultrasound (US) in the assessment of thyroid disease has greatly increased the detection of thyroid micro nodules not detected at clinical examination (Ezzat et al., 1994; Papini et al., 2011). Prospective studies have undertaken systematic evaluation of thyroid nodules incidentally discovered by US and have correlated size and the US and color-Doppler (CD) findings with the prevalence of cancer and its pathologic staging (Leenhardt et al., 1999). Several recent studies have suggested that US-detected PTMC (Figure 1) is a different disease entity from PTMC detected 
at autopsy, based on the histological findings and on the existence of some cases with poor prognosis (Sugitani and Fujimoto, 1999; Yamashita et al., 1999; Papini et al., 2002; Chow et al., 2003a; Pellegriti et al., 2004; Lo et al., 2006). The vast majority of non-palpable thyroid nodules identified by US and color-Doppler display a hypoechoic pattern, irregular margins, microcalcifications, and intranodular vascularity indicating risk for malignancy, which can be confirmed by cytological evaluation of FNA material. Due to the non-negligible prevalence of extra-capsular growth and nodal metastasis, US-guided FNA should be performed on all 8-15 mm hypoechoic nodules with irregular margins, intranodular vascular spots, or microcalcifications. Non-palpable thyroid lesions without US risk factors should be followed up after 612 months by repeating clinical and US evaluation (Papini et al., 2002).

\section{TREATMENT AND CLINICAL OUTCOME}

Treatment of PTMC has been addressed in both European Thyroid Association (ETA; Pacini et al., 2006) and American Thyroid Association (ATA; Cooper et al., 2009) guidelines. When PTMC is diagnosed preoperatively, routine total, or near-total thyroidectomy is the main treatment to eradicate multifocal disease and decrease overall recurrence rate. ATA guidelines for patients with differentiated thyroid cancer state that the benefit of radioiodine treatment appears to be restricted to patients with larger tumors $(>1.5 \mathrm{~cm})$ or residual disease after surgery. There is no evidence that there is any benefit of radioiodine treatment in lower risk patients (defined by the following criteria: PTMC with no extension beyond the thyroid capsule, unifocal tumor, no aggressive histologic subtypes, no extra thyroidal extension or angioinvasion, no local or distant metastases, complete resection of macroscopic tumor, and no ${ }^{131} \mathrm{I}$ uptake outside the thyroid bed on the post-therapeutic whole-body scan if ${ }^{131} \mathrm{I}$ was administered; Jonklaas et al., 2006; Cooper et al., 2009). Instead, the recommendation for radioactive iodine is supported by a study (Sakorafas et al., 2007) that followed 27 of 380 (7.1\%) patients diagnosed with incidental PTMC (mean diameter $4.4 \mathrm{~mm}$ ) following thyroid surgery for benign thyroid disease (20 patients with MNG, six patients with follicular adenoma, and one patient with nodular hyperplasia; Sakorafas et al., 2007). Patients with cytological preoperative diagnosis of thyroid malignancy were excluded from this study. In 11 patients $(40.7 \%)$, the tumor was multifocal and in about half of them tumor foci were found in both thyroid lobes. In two patients, PTMC infiltrated the thyroid capsule. Total/near-total thyroidectomy was performed in all these patients. All patients with incidental PTMC received suppression therapy and 20 underwent adjuvant radioactive iodine therapy at a dose of $80-100 \mathrm{mCi}$ based mainly on the presence of multifocal PTMC and infiltration of the thyroid capsule. Follow-up (mean 4.56 years, range 1-12 years) was completed in 25 patients; all of these were alive and disease-free. The authors of this study concluded that PTMC is not an uncommon incidental finding after surgery for benign thyroid lesions and that therefore the possibility of PTMC (in particular multifocal incidental PTMC) should be considered in the management of patients with benign thyroid disease. Also, total/near-total thyroidectomy should be considered in patients with apparently benign nodular thyroid disease who exhibit risk factors including findings from history and clinical examination (i.e., development of hoarseness, progressive dysphagia or shortness of breath, rapid growth of the thyroid nodule, especially if observed under thyroid hormone suppressive therapy, or presence of cervical lymphadenopathy) or suspicious findings on preoperative imaging evaluation.

Importantly, whether individual tumor foci in patients with multifocal PTC or PTMC are clonally related or they arise independently is still controversial. While Shattuck et al. (2005) demonstrated that individual tumor foci in patients with multifocal PTC often arise as independent tumors, McCarthy et al. (2006)
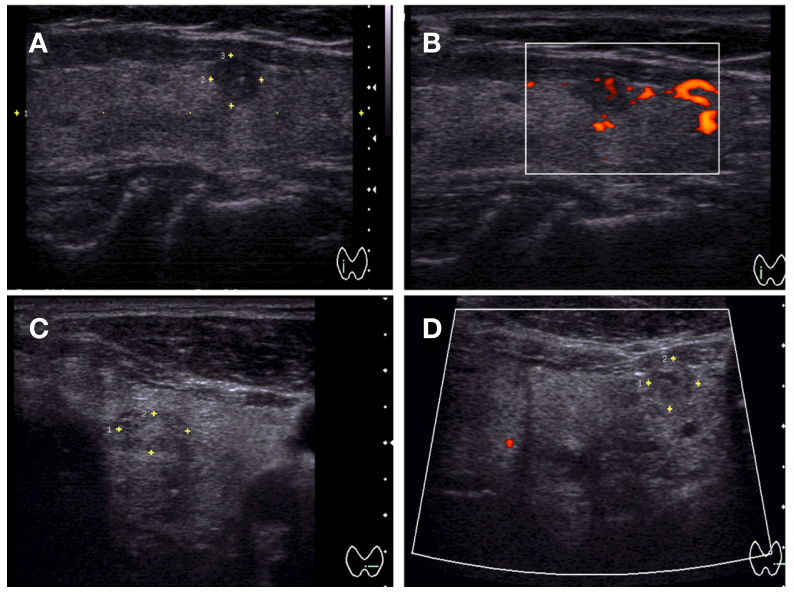
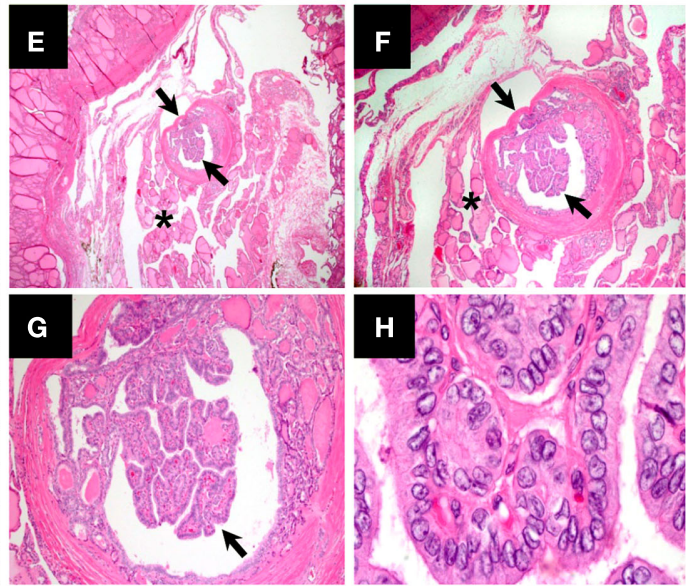

FIGURE 1 | Ultrasound and histological characteristics of a papillary thyroid microcarcinoma (PTMC) nodule. (A-B) Papillary thyroid microcarcinoma (PTMC) nodule $(5.8 \mathrm{~mm})$ with hypoechoic pattern, microcalcifications, well-defined margins, and intrinsic vascularity. (C-D) PTMC nodule $(6.3 \mathrm{~mm})$ with isoechoic or mixed echo texture, cystic elements, irregular margins, hypovascularity, and coarse or peripheral calcifications [also "taller than wider" in (D)]. (E-H) Histological features of $2 \mathrm{~mm}$ encapsulated PTMC with classical-type features in a multinodular goiter [arrows, (E-G)]: papillary structure with fibrovascular stalk, nuclear grooves, and nuclear pseudo inclusions (H). The tumor cells had pale eosinophilic cytoplasm with the characteristic vesicular to ground glass appearing nuclei (H) [Magnification: (E) 20x, (F) 40x, (G) 100x, and (F) 1000×]. 
demonstrated that multifocal PTC often arise from the same clone. Thus, intrathyroid metastasis may play an important role in the spread of PTC and PTMC (McCarthy et al., 2006), but the origin of multifocal tumors is unclear. Remarkably, some studies (Baudin et al., 1998; Chow et al., 2003a) have reported that the number and the size of tumor foci in PTMCs correlated with lymph node metastases at clinical presentation and with recurrence, suggesting that those pathologic features may represent relevant prognostic indicators in patients with PTMC. In fact, PTMC multifocality can be associated with high frequency of bilateral involvement regardless of tumor size (Baudin et al., 1998). Even when there is extended disease, the prognosis of patients with PTMCs is excellent, and the majority of studies report a mortality rate between 0 and $0.4 \%$ and a recurrence rate between 1.4 and $7.3 \%$ (Pazaitou-Panayiotou et al., 2007). However, there is some controversy regarding clinical outcome and treatment of PTMC, as evidenced in the following selected studies:

(i) Ito et al. (2003) followed 162 patients with lesions ranging from 3 to $10 \mathrm{~mm}$. In 58 of these, they studied the size of PTMC by ultrasound over 5 or more years. They found no change in $60.3 \%$ of these cases, a decrease in $12.1 \%$, and, in two patients, no identifiable cancer in two consecutive ultrasounds. Ito et al. (2004) also reported that PTMCs $\geq 7 \mathrm{~mm}$ were more likely to show lateral neck metastasis, suggesting that detailed US examination for lateral metastasis is necessary in patients with a tumor measuring $\geq 7 \mathrm{~mm}$.

(ii) Hay et al. (1992) evaluated 535 patients with PTMC with a median tumor size of $8 \mathrm{~mm}$. Two patients $(0.4 \%)$ died, and the 20 -year tumor recurrence rate was $6 \%$.

(iii) Roti et al. (2006) reported on 243 patients diagnosed with PTMC. One group consisted of 52 patients diagnosed with incidental PTMC following thyroidectomy for benign thyroid disease. The second group included 191 patients who underwent thyroidectomy because FNA biopsy of a thyroid nodule and/or clinical evaluation was diagnostic or suspicious for malignancy. No significant differences in clinical and histo-pathological characteristics were observed between the two groups. Mean PTMC diameter was $0.55 \pm 0.26 \mathrm{~cm}$ in the incidental group and $0.56 \pm 0.27 \mathrm{~cm}$ in the suspected cancer group. A total of 34 patients had neck node and/or distant metastases at the time of diagnosis. Distant metastases were only significantly observed in patients with PTMC $\geq 8 \mathrm{~mm}$. Thirty-two patients with PTMC with a diameter $\geq 5 \mathrm{~mm}$, and two with PTMC with a diameter $<5 \mathrm{~mm}$ had lymph node metastases (Roti et al., 2006). Lymph nodes and distant metastases from thyroid cancers with diameters of $8-15 \mathrm{~mm}$ have been also described in other studies (Lin et al., 1997; Sugitani et al., 1998; Nasir et al., 2000). Interestingly, Roti et al. (2006) reported only four patients (1.7\%) with recurrent or persistent disease, and no PTMC-related mortality. Similarly, an excellent outcome for PTMC has been described by other investigators (Bramley and Harrison, 1996; Noguchi et al., 1996; Rodriguez et al., 1997; Yamashita et al., 1999; Pelizzo et al., 2004), whereas other studies found persistent or recurrent disease in 6-14.4\% of patients with PTMC (Hay et al., 1992; Chow et al., 2003b; Pellegriti et al., 2004). (iv) One major issue with PTMC is the threshold value of tumor diameter and whether the outcome for slightly larger thyroid tumors (i.e., $1.1-1.5 \mathrm{~cm}$ in diameter) is similar to PTMC. Pellegriti et al. (2004) investigated predictors of relapse in PTMC vs. PTC between 1.1 and $1.5 \mathrm{~cm}$. The authors performed a retrospective study of 299 patients with PTC treated and followed up between 1975 and 2001. Near-total or total thyroidectomy was performed in 292 patients, and lobectomy in seven patients. This study indicated that a high proportion of $\mathrm{PTC} \leq 1.5 \mathrm{~cm}$ carry one or more risk factors at clinical presentation, including bilateral foci. In particular, authors found that approximately $20 \%$ of small $(\leq 1.5 \mathrm{~cm})$ PTCs had extra-thyroid invasion and/or bilateral foci. None of the 299 patients in this study died of the disease. However, $43(14.4 \%)$ patients still had persisting/recurrent disease at the last follow-up visit. PTC were subdivided into three groups according to their size (diameter: $<0.5,0.6-1.0$, and $1.1-1.5 \mathrm{~cm}$ ) and a progressively increasing frequency of signs of tumor aggressiveness (multifocality, bilaterality, extrathyroidal invasion, and lymph node involvement) which correlated with increasing tumor size. This was particularly evident for PTC greater than $1.0 \mathrm{~cm}$ vs. PTC less $1.0 \mathrm{~cm}$ in diameter (Pellegriti et al., 2004).

(v) Presence or absence of risk factors/aggressiveness features are important indicators in planning thyroid surgery for PTMC (e.g., lobectomy alone vs. total thyroidectomy with central compartment neck dissection). Previous studies have shown considerable variability in the prevalence of aggressive features and but significant differences between PTMC and PTC in the prevalence of aggressive features. This was addressed in a recent study (Yun et al., 2010) that found that out of 87 patients (preoperative retrospective study), 44 (51\%) had extra thyroidal extension, and 27 (31\%) had central lymph node metastasis. Positron emission tomography (PET)/Computed tomography (CT) showed discernible fluorodeoxyglucose (FDG) uptake in 46 PTMCs (53\%). FDG positivity of PTMCs was the only variable that correlated with both extra thyroidal extension and central lymph node metastasis; there was a significant difference in the prevalence of both extra thyroidal extension (70 vs. 29\%) and central lymph node metastasis ( 41 vs. $19.5 \%$ ) between FDGpositive and -negative groups. The authors concluded that visual FDG positivity in PTMCs is a potential risk factor that may be useful for preoperative risk stratification. However, this study lacked long-term follow-up of correlation of FDG positivity in PTMCs with disease relapse rate, thus prospective studies are needed to assess the long-term benefit, cost effectiveness, sensitivity, and specificity of FDG-PET in patients with PTMC.

(vi) Importantly, Biscolla et al. (2004) have reported that PTMC can be associated with medullary thyroid cancer (MTC). Twenty-seven of 196 (13.8\%) MTC cases showed an association with PTC, and 21 of 190 (11\%) MTC showed an association with incidental PTMC. This percentage is higher than that reported in the literature on the association of PTMC with Graves' disease (GD; $2.8 \%-4.5 \%$; Schwartz et al., 1989; Mazzaferri, 1990; Hori et al., 1995; Merchant et al., 
2002) or with MNG (3\%; Pelizzo et al., 1997). The authors excluded the possibility that this association was caused by an increase in the general frequency of PTMC. Furthermore, although it was not possible to completely exclude a shared pathogenic event as the cause of both MTC and PTMC, the molecular analysis of RET gene alterations did not show any common mutation between these two types of thyroid cancers. The clinical behavior of MTC does not seem to be influenced by the presence or specific therapeutic treatment of a concomitant PTMC (Biscolla et al., 2004).

In summary, total or near-total thyroidectomy is the treatment of choice in patients with PTC followed by radioactive iodine ablation, in case of a tumor size greater than $1.0 \mathrm{~cm}$ or the presence of lymph node or distant metastasis, to achieve negative ${ }^{131}$ I whole-body scan and undetectable thyroglobulin (Tg) levels during follow-up. Levothyroxine (LT4) suppressive therapy is recommended for high risk thyroid cancers patients. Post-surgical radioiodine treatment in the case of patients with PTMC (tumor size less or equal to $1 \mathrm{~cm}$ in diameter) is clearly indicated in the presence of high risk factors, but can be avoided in patients with low-risk (unifocal tumor, no extra thyroidal extension, no tall cell variant, columnar cell, diffuse sclerosing, and solid/trabecular variants, and no lymph node, or distant metastases; Falvo et al., 2003; Pazaitou-Panayiotou et al., 2007).

\section{GENETIC ALTERATIONS IN PTMC}

The search for molecular targets for PTC has focused primarily on the RET (tyrosine kinase receptor)/RAS/BRAF/MAPK (mitogenactivated extracellular signal regulated kinase, i.e., ERK1/2) kinase signaling pathway as the oncogenic event in PTC progression (Xing, 2007; Nucera et al., 2010, 2011a,b; Knauf et al., 2011; Ringel, 2011). The major genetic alterations so far described in PTC are translocations in the RET gene (the estimated prevalence is highly variable between different studies, from 3 to $92 \%$, and depends on the experimental methodology used) and the V600E point mutation in the BRAF gene (Nikiforova et al., 2003; Xing, 2007; Marotta et al., 2011), which occurs in about $50 \%$ of PTC. Both of these genetic alterations trigger the ERK1/2 pathway, which causes abnormal cell proliferation, adhesion, migration, and invasion (Melillo et al., 2005; Nucera et al., 2010, 2011b; Knauf et al., 2011).

A high prevalence (about 45-52\%) of RET/PTC translocations has been reported in PTMCs (Tallini et al., 1998; Corvi et al., 2001), suggesting that the activation of this oncogene (RET/PTC) plays a role in the early stage in PTMC development.

The BRAF ${ }^{\mathrm{V} 600 \mathrm{E}}$ mutation appears to occur early in PTC development, based on evidence that it is also harbored in PTMC (Sedliarou et al., 2004; Xing, 2007; Frasca et al., 2008; Nucera et al., 2009) and plays an important role in cell proliferation by regulating cyclins (e.g., cyclins D1 and p27; Motti et al., 2007; Xing, 2007; Salerno et al., 2010; Nucera et al., 2011b; Figure 2). Although the overall prevalence of the $\mathrm{BRAF}^{\mathrm{V} 600 \mathrm{E}}$ mutation in PTC worldwide is relatively high (Xing, 2007), the prevalence of this mutation in PTMC is generally much lower in many parts of the world (Lupi et al., 2007; Ugolini et al., 2007; Frasca et al., 2008) and as low as $18 \%$ in PTMC less than $5 \mathrm{~mm}$ in diameter (Ugolini et al., 2007). Excluding the areas in Korea where the BRAF ${ }^{\mathrm{V} 600 \mathrm{E}}$ mutation in PTMC is high (Xing, 2007), the overall frequency of the $\mathrm{BRAF}^{\mathrm{V} 600 \mathrm{E}}$ mutation in PTMC is around $30 \%$ (Xing, 2007). Lee et al. (2009) studied the clinico-pathological characteristics and

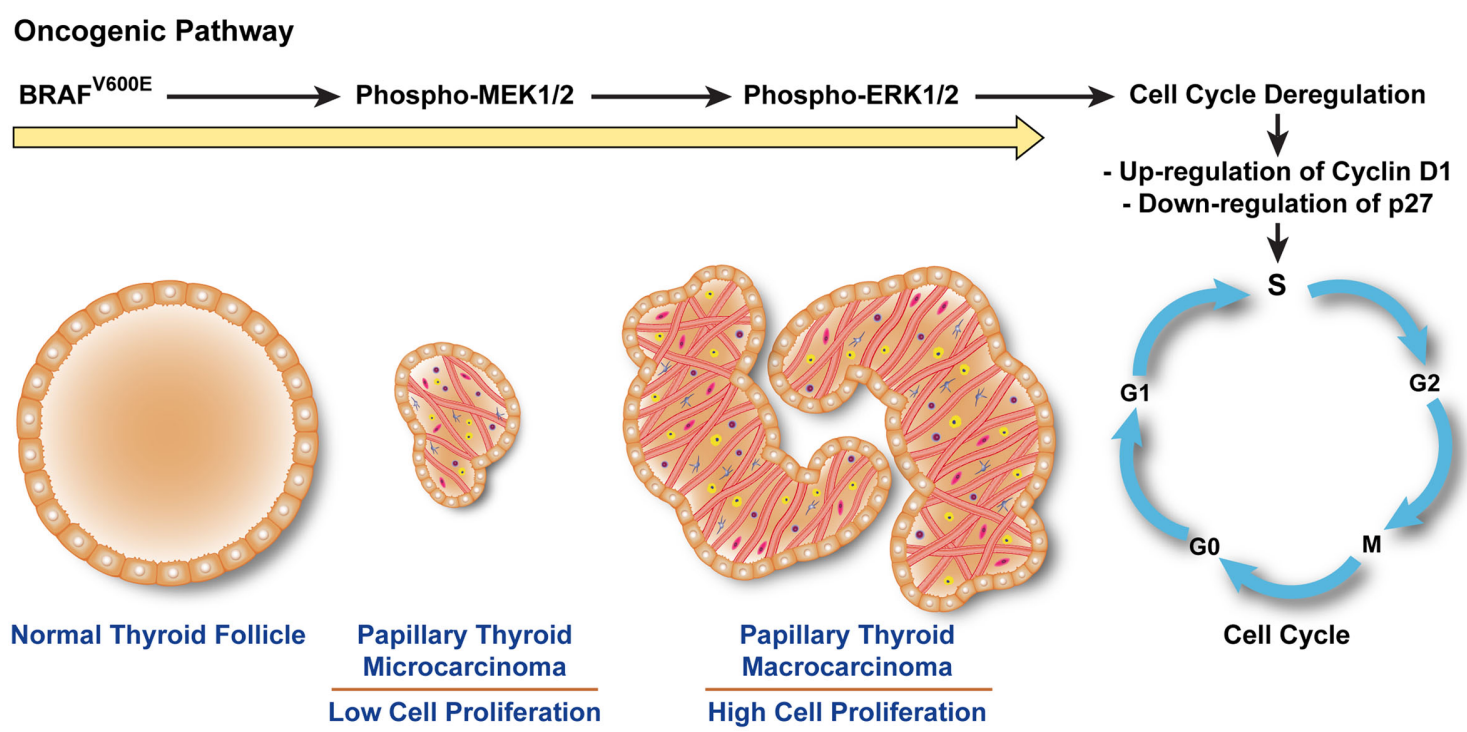

FIGURE 2 | BRAF ${ }^{600 E}$ triggers a cascade that leads to human papillary thyroid microcarcinoma (PTMC) proliferation. The constitutive kinase activity of BRAF ${ }^{\mathrm{V} 00 \mathrm{E}}$ phosphorylates and activates MEK1/2. Phospho-MEK1/2 induces hyperphosphorylation of ERK1/2 which translocates into the nucleus, triggering cell cycle progression, and abnormal cell proliferation by up-regulating cyclins (e.g., Cyclin D1) crucial for the checkpoint machinery in G1-S phases and inhibiting anti-cell cycle cyclins (e.g., p27). Up-regulation of cyclins (e.g., Cyclin D1) leads to hyper-proliferation of papillary thyroid microcarcinoma cells and increase in papillae size. 
the BRAF ${ }^{\mathrm{V} 600 \mathrm{E}}$ mutational status of 64 cases of PTMCs. BRAF ${ }^{\mathrm{V} 600 \mathrm{E}}$ mutation was detected in $37.5 \%$ of PTMCs. BRAF ${ }^{\mathrm{V} 600 \mathrm{E}}$-positive PTMCs exhibited significantly more features of aggressiveness (advanced disease stages, extra thyroidal extension, and nodal metastasis) than PTMCs without the V600E mutation, indicating that $\mathrm{BRAF}^{\mathrm{V} 600 \mathrm{E}}$ may be a marker of aggressiveness and tumor progression from PTMC to PTC. Fifty percent of $\mathrm{BRAF}^{\mathrm{V} 600 \mathrm{E}}$-positive PTMCs were stage III or IV. These data indicate that the BRAF ${ }^{V 600 E}$ mutation might be a molecular marker of tumor invasiveness and, moreover, that this relationship is independent of tumor size (e.g., greater than $1.1 \mathrm{~cm}$ vs. less than $1 \mathrm{~cm}$ ).

Recently, Niemeier et al. (2011) analyzed a group of aggressive PTMC selected based on the presence of lymph node metastasis or tumor recurrence and compared with a group of non-aggressive PTMC. The groups were matched for age, sex, and tumor size, but with no extra thyroidal spread (significantly more prevalent in the aggressive group). Importantly, these authors detected $\mathrm{BRAF}^{\mathrm{V} 600 \mathrm{E}}$ in $77 \%$ of aggressive and $32 \%$ of non-aggressive PTMCs, suggesting that the $\mathrm{V} 600 \mathrm{E}$ mutation may be a marker of invasiveness and, together with histo-pathologic features of aggressiveness, may allow clinical risk stratification of PTMCs.

The BRAF ${ }^{\mathrm{V} 600 \mathrm{E}}$ mutation has been correlated with multifocality pathologic features in thyroid cancers (Xing, 2007). As is the case for PTC, the importance of the distinction between multifocal independent primary (IP) PTMC and PTMC with intrathyroid metastasis is unclear. Incidental PTMC can be multifocal (Lin et al., 2008) and associated with lymph node metastases and increased neck lymph nodes recurrence after surgical treatment. Lin et al. (2008) found that the incidence of lymph node metastasis for multifocal PTMC was 42.9\%, similar to previous studies (David et al., 1992; Rodriguez et al., 1997; Baudin et al., 1998; Arem et al., 1999). Lin et al. also found that a high percentage (75\%) of PTMC with intrathyroid metastasis were positive for lymph node metastasis, while no patients with multifocal IP PTMC had metastatic disease. This suggests that it is important to separate PTMC with intrathyroid metastasis from multifocal IP tumors. In this study, about 50\% of multifocal PTMCs showed intrathyroidal metastasis; the molecular profile of this group of PTMCs was characterized by loss of heterozygosities (LOHs) at chromosomes 1p36, 18q21, and 22q13, and/or BRAF ${ }^{\mathrm{V} 600 \mathrm{E}}$ mutation, suggesting that both different chromosomal losses and point mutations in the BRAF gene could be important pathological events in the origin of multifocal PTMC.

In summary, there is good evidence that $\mathrm{BRAF}^{\mathrm{V} 600 \mathrm{E}}$-positive PTMC are more likely to have a poor prognosis and therefore, it seems reasonable to be more aggressive in treating patients with PTMC carrying the BRAF ${ }^{\mathrm{V} 600 \mathrm{E}}$ mutation. Soares and SobrinhoSimoes (2011) recently suggested that genetic screening for the $\mathrm{BRAF}^{\mathrm{V} 600 \mathrm{E}}$ mutation might also help assess risk stratification and manage patients with PTMC. PTMC without BRAF ${ }^{\mathrm{V} 600 \mathrm{E}}$ may be conservatively managed unless the presence of other markers of poor prognosis indicate a more aggressive therapeutic approach (Xing, 2009).

\section{MOLECULAR PATHWAYS IN PTMC}

Since most PTMC progress very slowly while others show more aggressive behavior, it would be clinically relevant to determine a gene signature that can predict tumor aggressiveness. Few studies have focused on the molecular pathways that underlie the pathobiology of PTMC. Kim et al. (2010) recently performed oligonucleotide array analysis of PTMC and found that cell adhesion molecules were up-regulated in PTMC. In addition, they found no differences in gene expression between PTMC and PTC, suggesting that some PTMC may not be occult indolent thyroid cancers but are an earlier stage of PTC.

Min et al. (2008) found that PTMC with extra thyroidal extension and multifocality exhibited significant expression of S100A4 and that its expression predicted lymph node metastasis. S100A4 (Garrett et al., 2006) is a member of the S100 family of calciumbinding proteins, which includes metastasin, fibroblast-specific protein, pEL-98, 18A2, CAPL, and calvasculin. In vitro and in vivo studies in rodents have provided evidence that S100A4 is directly involved in tumor progression and metastasis, and promotes angiogenesis. Therefore, preoperative evaluation of the expression of S100A4 in cytological specimens should be helpful in guiding therapy for patients with PTMCs. S100A4 immunoreactivity may predict lymph node metastasis in PTMC and might therefore be useful as an immunohistochemical marker to distinguish between more aggressive PTMC and clinically indolent PTMC.

\section{TARGETED THERAPIES WITH SELECTIVE AND NON-SELECTIVE INHIBITORS OF BRAFV600E}

Chemotherapies for metastatic thyroid carcinomas have been of limited effectiveness. Therefore, novel therapies are needed to improve disease outcome for patients with these cancers. Studies based on preclinical models of targeted therapies highlight the importance of individualized genomic profiling to guide patient selection for inclusion in clinical trials.

Some drugs that target the $\mathrm{BRAF}^{\mathrm{V} 600 \mathrm{E}}$ oncoprotein kinase have recently begun clinical trials in patients with melanoma. Selective pharmacologic targeting of $\mathrm{BRAF}^{\mathrm{V} 600 \mathrm{E}}$ may prove effective for treating patients with PTC harboring this mutation. For example, PLX4720 and PLX4032 are novel orally available selective small molecule inhibitors specifically designed to insert into the ATP-binding site and trap oncogenic $\mathrm{BRAF}^{\mathrm{V} 600 \mathrm{E}}$ in an inactive conformation (Tsai et al., 2008; Bollag et al., 2010). These compounds inhibit $\mathrm{BRAF}^{\mathrm{V} 600 \mathrm{E}}$ kinase activity in melanoma, thyroid cancer, and colorectal cancer cells (Tsai et al., 2008; Nucera et al., 2010). PLX4032 (Vemurafenib) induced complete or partial tumor regression in $81 \%$ of patients enrolled for phase I-II clinical trial who had melanoma with the BRAF ${ }^{\mathrm{V} 600 \mathrm{E}}$ mutation (Flaherty et al., 2010). In addition, it significantly improved rates of overall survival and progression-free survival $(74 \%)$ in phase III clinical trials in $\mathrm{BRAF}^{\mathrm{V} 600 \mathrm{E}}$-positive melanoma patients (Chapman et al., 2011). The effect of PLX4720 in a preclinical model of metastatic human thyroid cancer suggests that these inhibitors might be effective for treating patients with $\mathrm{BRAF}^{\mathrm{V} 600 \mathrm{E}}$-positive thyroid cancers that are refractory to conventional therapy (Nucera et al., 2010).

Interestingly, overexpression of angiogenic signaling cascade pathways has been described in human PTC, and preclinical models have shown that inhibition of key molecules (i.e., protein kinases) in these pathways can have anti-tumor effects (Gild et al., 2011). Some of these kinase inhibitors have now been tested in clinical trials, with modest results. For example, Sorafenib was designed as a c-RAF inhibitor; however, it has been reported to 
target other kinases, including vascular endothelial growth factor receptors (VEGFR) and $\mathrm{BRAF}^{\mathrm{V} 600 \mathrm{E}}$, therefore, it has been classified as non-selective inhibitor of BRAF ${ }^{\mathrm{V} 600 \mathrm{E}}$. Sorafenib has been assessed clinically in patients with $\mathrm{BRAF}^{\mathrm{V} 600 \mathrm{E}}$-positive or genetically unknown advanced melanoma and did not show any benefit in those clinical trials (Hauschild et al., 2009; Ott et al., 2010; Caronia et al., 2011). Additionally, in phase I-II clinical trials, only $15 \%$ of patients with metastatic PTC showed a partial response to Sorafenib (Kloos et al., 2009; Caronia et al., 2011).

Although only a small percentage of all PTMC are metastatic, $\sim 77 \%$ of BRAF $^{\mathrm{V} 600 \mathrm{E}}$-positive PTMC show features associated with aggressiveness (i.e., extra thyroidal extension; Niemeier et al., 2011). For these tumors, targeted therapies based on selective inhibitors of $\mathrm{BRAF}^{\mathrm{V} 600 \mathrm{E}}$ could be effective in the near future.

\section{CONCLUSION AND PERSPECTIVES}

The management and treatment of malignant thyroid micro nodules (i.e., PTMC) can be a challenge for physicians. Most PTMC are indolent and have an excellent prognosis; however, a subgroup shows an aggressive biological and clinical behavior similar to PTC. While additional robust prospective studies are required, there is now a body of evidence suggesting that $\mathrm{BRAF}^{\mathrm{V} 600 \mathrm{E}}$-positive PTMCs show aggressive behavior, whereas $\mathrm{BRAF}^{\mathrm{V} 600 \mathrm{E}}$-negative PTMCs have a good prognosis. This suggests that it will be valuable to consider the BRAF ${ }^{\mathrm{V} 600 \mathrm{E}}$ mutation as a prognostic marker of PTMC aggressiveness and to undertake prospective studies with systematic screening for the BRAF ${ }^{\mathrm{V} 600 \mathrm{E}}$ mutation and long-term follow-up to validate this marker of tumor aggressiveness.

\section{REFERENCES}

Arem, R., Padayatty, S. J., Saliby, A. H., and Sherman, S. I. (1999). Thyroid microcarcinoma: prevalence, prognosis, and management. Endocr. Pract. 5, 148-156.

Barbaro, D., Simi, U., Meucci, G., Lapi, P., Orsini, P., and Pasquini, C. (2005). Thyroid papillary cancers: microcarcinoma and carcinoma, incidental cancers and non-incidental cancers - are they different diseases? Clin. Endocrinol. (Oxf.) 63, 577-581.

Baudin, E., Travagli, J. P., Ropers, J., Mancusi, F., Bruno-Bossio, G., Caillou, B., Cailleux, A. F., Lumbroso, J. D., Parmentier, C., and Schlumberger, M. (1998). Microcarcinoma of the thyroid gland: the GustaveRoussy Institute experience. Cancer $83,553-559$

Biscolla, R. P., Ugolini, C., Sculli, M., Bottici, V., Castagna, M. G., Romei, C., Cosci, B., Molinaro, E., Faviana, P., Basolo, F., Miccoli, P., Pacini, F., Pinchera, A., and Elisei, R. (2004). Medullary and papillary tumors are frequently associated in the same thyroid gland without evidence of reciprocal influence in their biologic behavior. Thyroid 14, 946-952.

Bollag, G., Hirth, P., Tsai, J., Zhang, J., Ibrahim, P. N., Cho, H., Spevak, W.,

A validated marker would help endocrinologists and oncologists stratify clinical risk in PTMC. Although, additional biological studies are needed to address definitively whether PTMC is an indolent cancer or an early stage of PTC, current clinical and molecular data suggest that patients with PTMCs that harbor the $\mathrm{BRAF}^{\mathrm{V} 600 \mathrm{E}}$ mutation and exhibit aggressive clinical-pathologic features may benefit from treatment with $\mathrm{BRAF}^{\mathrm{V} 600 \mathrm{E}}$-selective inhibitors. There is sufficient promising preclinical experimental data to suggest that physicians could begin to test such targeted treatments now, preferably in the context of a prospective clinical trial following patients with aggressive $\mathrm{BRAF}^{\mathrm{V} 600 \mathrm{E}}$ expressing PTMC.

\section{ACKNOWLEDGMENTS}

Carmelo Nucera $(\mathrm{MD}, \mathrm{PhD})$ is a New Investigator funded from the American Thyroid Association (ATA, Grants 2011) for Thyroid Cancer Research and he was also funded through "A. Gemelli" Medical School (Catholic University, Roma). Carmelo Nucera was recipient of Ph.D. fellowship from the Italian Ministry of Education, Universities and Research (MIUR) and carried out research work at Harvard Medical School. We thank Professor Peter M. Sadow (Endocrine Pathology, Massachusetts General Hospital, Harvard Medical School, Boston, USA) and Dr. Francesca Ianni (Policlinico A. Gemelli, Catholic University, Roma) for providing $\mathrm{H} \& \mathrm{E}$ and ultrasound images, respectively. We thank those authors whom we were not able to cite because of limited space.

with BRAFV600E mutation. N. Engl. J. Med. 364, 2507-2516.

Zhang, C., Zhang, Y., Habets, Burton, E. A., Wong, B., Tsang, G. West, B. L., Powell, B., Shellooe, R., Marimuthu, A., Nguyen, H., Zhang, K. Y., Artis, D. R., Schlessinger, J., Su, F., Higgins, B., Iyer, R., D’Andrea, K., Koehler, A., Stumm, M., Lin, P. S., Lee, R. J., Grippo, J., Puzanov, I., Kim, K. B., Ribas, A., McArthur, G. A., Sosman, J. A., Chapman, P. B., Flaherty, K. T., Xu, X., Nathanson, K. L., and Nolop, K. (2010). Clinical efficacy of a RAF inhibitor needs broad target blockade in BRAF-mutant melanoma. Nature 467, 596-599.

Bramley, M. D., and Harrison, B. J. (1996). Papillary microcarcinoma of the thyroid gland. Br. J. Surg. 83, 1674-1683.

Caronia, L. M., Phay, J. E., and Shah, M. H. (2011). Role of BRAF in thyroid oncogenesis. Clin. Cancer Res. 17, 7511-7517.

Chapman, P. B., Hauschild, A., Robert, C., Haanen, J. B., Ascierto, P., Larkin, J., Dummer, R., Garbe, C., Testori, A., Maio, M., Hogg, D., Lorigan, P., Lebbe, C., Jouary, T., Schadendorf, D., Ribas, A., O’Day, S. J., Sosman, J. A., Kirkwood, J. M., Eggermont, A. M., Dreno, B., Nolop, K., Li, J., Nelson, B., Hou, J., Lee, R. J., Flaherty, K. T., McArthur, G. A., and BRIM-3 Study Group. (2011). Improved survival with vemurafenib in melanoma
Chow, S. M., Law, S. C., Chan, J. K., $\mathrm{Au}, \mathrm{S}$. K., Yau, S., and Lau, W. H. (2003a). Papillary microcarcinoma of the thyroid-Prognostic significance of lymph node metastasis and multifocality. Cancer 98, 31-40.

Chow, S. M., Law, S. C., Au, S. K., Mang, O., Yau, S., Yuen, K. T., and Lau, W. H. (2003b). Changes in clinical presentation, management and outcome in 1348 patients with differentiated thyroid carcinoma: experience in a single institute in Hong Kong, 19602000. Clin. Oncol. (R. Coll. Radiol.) 15, 329-336.

Cooper, D. S., Doherty, G. M., Haugen, B. R., Kloos, R. T., Lee, S. L., Mandel, S. J., Mazzaferri, E. L., McIver, B., Pacini, F., Schlumberger M., Sherman, S. I., Steward, D. L., and Tuttle, R. M. (2009). Revised American Thyroid Association management guidelines for patients with thyroid nodules and differentiated thyroid cancer. Thyroid 19, 1167-1214.

Corvi, R., Martinez-Alfaro, M., Harach, H. R., Zini, M., Papotti, M., and Romeo, G. (2001). Frequent RET rearrangements in thyroid papillary microcarcinoma detected by interphase fluorescence in situ hybridization. Lab. Invest. 81, 1639-1645.
David, J. M., Ruaux, C., Bachaud, J. M., Bonnet, F., Lucot, H., Boneu, A., Suc, E., and Cabarrot, E. (1992). Multiple localization and lymphatic involvement of papillary microcarcinoma of the thyroid. Results of total thyroidectomy with bilateral lymph node excision. Apropos of 38 patients. Ann. Otolaryngol. Chir. Cervicofac. 109, 183-187.

Davies, L., and Welch, H. G. (2006). Increasing incidence of thyroid cancer in the United States, 1973-2002. JAMA 295, 2164-2167.

Ezzat, S., Sarti, D. A., Cain, D. R., and Braunstein, G. D. (1994). Thyroid incidentalomas. Prevalence by palpation and ultrasonography. Arch. Intern. Med. 154, 1838-1840.

Falvo, L., D'Ercole, C., Sorrenti, S., D’Andrea, V., Catania, A., Berni, A., Grilli, P., and De Antoni, E. (2003). Papillary microcarcinoma of the thyroid gland: analysis of prognostic factors including histological subtype. Eur. J. Surg. Suppl. 588, 28-32.

Flaherty, K. T., Puzanov, I., Kim, K. B., Ribas, A., McArthur, G. A., Sosman, J. A., O’Dwyer, P. J., Lee, R. J., Grippo, J. F., Nolop, K., and Chapman, P. B. (2010). Inhibition of mutated, activated BRAF in metastatic melanoma. N. Engl. J. Med. 363, 809-819. 
Frasca, F., Nucera, C., Pellegriti, G., Gangemi, P., Attard, M., Stella, M., Loda, M., Vella, V., Giordano, C., Trimarchi, F., Mazzon, E., Belfiore, A., and Vigneri, R. (2008). BRAF(V600E) mutation and the biology of papillary thyroid cancer. Endocr. Relat. Cancer 15, 191-205.

Garrett, S. C., Varney, K. M., Weber, D. J., and Bresnick, A. R. (2006). S100A4, a mediator of metastasis. J. Biol. Chem. 281, 677-680.

Gild, M. L., Bullock, M., Robinson, B. G., and Clifton-Bligh, R. (2011). Multikinase inhibitors: a new option for the treatment of thyroid cancer. Nat Rev Endocrinol 7, 617-624.

Hauschild, A., Agarwala, S. S., Trefzer, U., Hogg, D., Robert, C., Hersey, P., Eggermont, A., Grabbe, S., Gonzalez, R., Gille, J., Peschel, C., Schadendorf, D., Garbe, C., O’Day, S., Daud, A., White, J. M., Xia, C., Patel, K., Kirkwood, J. M., and Keilholz, U. (2009). Results of a phase III, randomized, placebo-controlled study of sorafenib in combination with carboplatin and paclitaxel as second-line treatment in patients with unresectable stage III or stage IV melanoma. J. Clin. Oncol. 27, 2823-2830.

Hay, I. D., Grant, C. S., van Heerden, J. A., Goellner, J. R., Ebersold, J. R., and Bergstralh, E. J. (1992). Papillary thyroid microcarcinoma: a study of 535 cases observed in a 50year period. Surgery 112, 1139-1146; discussion 1146-1137.

Hori, Y., Kashima, K., Daa, T., Yokoyama, S., Nakayama, I., and Noguchi, S. (1995). Relationship between cell proliferation activity and morphological characteristics of papillary microcarcinoma in the thyroid of Graves' disease. Pathol. Int. 45, 846-853.

Ito, Y., Tomoda, C., Uruno, T., Takamura, Y., Miya, A., Kobayashi, K., Matsuzuka, F., Kuma, K., and Miyauchi, A. (2004). Papillary microcarcinoma of the thyroid: how should it be treated? World J. Surg. 28, 1115-1121

Ito, Y., Uruno, T., Nakano, K., Takamura, Y., Miya, A., Kobayashi, K., Yokozawa, T., Matsuzuka, F., Kuma, S., Kuma, K., and Miyauchi, A. (2003). An observation trial without surgical treatment in patients with papillary microcarcinoma of the thyroid. Thyroid 13, 381-387.

Jonklaas, J., Sarlis, N. J., Litofsky, D., Ain, K. B., Bigos, S. T., Brierley, J. D., Cooper, D. S., Haugen, B. R., Ladenson, P. W., Magner, J., Robbins, J., Ross, D. S., Skarulis, M., Maxon, H. R., and Sherman, S. I.
(2006). Outcomes of patients with differentiated thyroid carcinoma following initial therapy. Thyroid 16, 1229-1242.

Kim, H. Y., Park, W. Y., Lee, K. E., Park, W. S., Chung, Y. S., Cho, S. J., and Youn, Y. K. (2010). Comparative analysis of gene expression profiles of papillary thyroid microcarcinoma and papillary thyroid carcinoma. $J$. Cancer. Res. Ther. 6, 452-457.

Kloos, R. T., Ringel, M. D., Knopp, M. V., Hall, N. C., King, M., Stevens, R., Liang, J., Wakely, P. E. Jr., Vasko, V. V., Saji, M., Rittenberry, J., Wei, L., Arbogast, D., Collamore, M., Wright, J. J., Grever, M., and Shah, M. H. (2009). Phase II trial of sorafenib in metastatic thyroid cancer. J. Clin. Oncol. 27, 1675-1684.

Knauf, J. A., Sartor, M. A., Medvedovic, M., Lundsmith, E., Ryder, M., Salzano, M., Nikiforov, Y. E., Giordano, T. J., Ghossein, R. A., and Fagin, J. A. (2011). Progression of BRAF-induced thyroid cancer is associated with epithelial-mesenchymal transition requiring concomitant MAP kinase and TGFbeta signaling. Oncogene 30, 3153-3162.

Lee, X., Gao, M., Ji, Y., Yu, Y., Feng, Y., Li, Y., Zhang, Y., Cheng, W., and Zhao, W. (2009). Analysis of differential BRAF(V600E) mutational status in high aggressive papillary thyroid microcarcinoma. Ann. Surg. Oncol. 16, 240-245.

Leenhardt, L., Grosclaude, P., and Cherie-Challine, L. (2004). Increased incidence of thyroid carcinoma in france: a true epidemic or thyroid nodule management effects? Report from the French Thyroid Cancer Committee. Thyroid 14, 1056-1060.

Leenhardt, L., Hejblum, G., Franc, B., Fediaevsky, L. D., Delbot, T., Le Guillouzic, D., Menegaux, F., Guillausseau, C., Hoang, C., Turpin, G., and Aurengo, A. (1999). Indications and limits of ultrasoundguided cytology in the management of nonpalpable thyroid nodules. $J$. Clin. Endocrinol. Metab. 84, 24-28.

Lin, K. D., Lin, J. D., Huang, H. S., Jeng, L. B., and Ho, Y. S. (1997). Skull metastasis with brain invasion from thyroid papillary microcarcinoma. $J$. Formos. Med. Assoc. 96, 280-282.

Lin, X., Finkelstein, S. D., Zhu, B., and Silverman, J. F. (2008). Molecular analysis of multifocal papillary thyroid carcinoma. J. Mol. Endocrinol. 41, 195-203.

Lloyd, R., De Lellis, R., Heitz, P., and Eng, C. (2004). World Health Organization Classification of Tumours:
Pathology and Genetics of Tumours of the Endocrine Organs. Lyon: IARC Press.

Lo, C. Y., Chan, W. F., Lang, B. H., Lam, K. Y., and Wan, K. Y. (2006). Papillary microcarcinoma: is there any difference between clinically overt and occult tumors? World J. Surg. 30, 759-766.

Lupi, C., Giannini, R., Ugolini, C., Proietti, A., Berti, P., Minuto, M., Materazzi, G., Elisei, R., Santoro, M. Miccoli, P., and Basolo, F. (2007) Association of BRAF V600E mutation with poor clinicopathological outcomes in 500 consecutive cases of papillary thyroid carcinoma. J. Clin. Endocrinol. Metab. 92, 4085-4090.

Marotta, V., Guerra, A., Sapio, M. R., and Vitale, M. (2011). RET/PTC rearrangement in benign and malignant thyroid diseases: a clinical standpoint. Eur. J. Endocrinol. 165 499-507.

Mazzaferri, E. L. (1990). Thyroid cancer and Graves' disease. J. Clin Endocrinol. Metab. 70, 826-829.

McCarthy, R. P., Wang, M., Jones, T. D., Strate, R. W., and Cheng, L. (2006). Molecular evidence for the same clonal origin of multifocal papillary thyroid carcinomas. Clin. Cancer Res. 12, 2414-2418.

McDougall, I. R., and Camargo, C. A. (2007). Treatment of micropapillary carcinoma of the thyroid: where do we draw the line? Thyroid 17, 1093-1096.

Melillo, R. M., Castellone, M. D., Guarino, V., De Falco, V., Cirafici, A. M. Salvatore, G., Caiazzo, F., Basolo, F., Giannini, R., Kruhoffer, M., Orntoft, T., Fusco, A., and Santoro, M. (2005). The RET/PTC-RAS-BRAF linear signaling cascade mediates the motile and mitogenic phenotype of thyroid cancer cells. J. Clin. Invest. 115, 1068-1081.

Merchant, F. H., Hirschowitz, S. L., Cohan, P., Van Herle, A. J., and Natarajan, S. (2002). Simultaneous occurrence of medullary and papillary carcinoma of the thyroid gland identified by fine needle aspiration. A case report. Acta Cytol. 46, 762-766.

Min, H. S., Choe, G., Kim, S. W., Park, Y. J., Park do, J., Youn, Y. K., Park, S. H., Cho, B. Y., and Park, S. Y. (2008). S100A4 expression is associated with lymph node metastasis in papillary microcarcinoma of the thyroid. Mod. Pathol. 21, 748-755.

Motti, M. L., De Marco, C., Califano, D., De Gisi, S., Malanga, D., Troncone, G., Persico, A., Losito, S., Fabiani, F., Santoro, M., Chiappetta, G. Fusco, A., and Viglietto, G. (2007).
Loss of p27 expression through RAS $\rightarrow$ BRAF $\rightarrow$ MAP kinase-dependent pathway in human thyroid carcinomas. Cell Cycle 6, 2817-2825.

Nasir, A., Chaudhry, A. Z., Gillespie, J., and Kaiser, H. E. (2000). Papillary microcarcinoma of the thyroid: a clinico-pathologic and prognostic review. In vivo 14, 367-376.

Niemeier, L. A., Kuffner Akatsu, H., Song, C., Carty, S. E., Hodak, S. P. Yip, L., Ferris, R. L., Tseng, G. C., Seethala, R. R., Lebeau, S. O., Stang, M. T., Coyne, C., Johnson, J. T., Stewart, A. F., and Nikiforov, Y. E. (2011). A combined molecular-pathologic score improves risk stratification of thyroid papillary microcarcinoma. Cancer. doi: 10.1002/cncr.26425. [Epub ahead of print].

Nikiforova, M. N., Kimura, E. T., Gandhi, M., Biddinger, P. W., Knauf, J. A., Basolo, F., Zhu, Z., Giannini, R., Salvatore, G., Fusco, A., Santoro, M., Fagin, J. A., and Nikiforov, Y. E. (2003). BRAF mutations in thyroid tumors are restricted to papillary carcinomas and anaplastic or poorly differentiated carcinomas arising from papillary carcinomas. J. Clin. Endocrinol. Metab. 88, 5399-5404.

Noguchi, S., Yamashita, H., Murakami, N., Nakayama, I., Toda, M., and Kawamoto, H. (1996). Small carcinomas of the thyroid. A long-term follow-up of 867 patients. Arch. Surg. 131, 187-191.

Nucera, C., Goldfarb, M., Hodin, R., and Parangi, S. (2009). Role of B$\mathrm{Raf}(\mathrm{V} 600 \mathrm{E})$ in differentiated thyroid cancer and preclinical validation of compounds against BRaf(V600E). Biochim. Biophys. Acta 1795, 152-161.

Nucera, C., Lawler, J., and Parangi, S. (2011a). BRAFV600E and microenvironment in thyroid cancer: a functional link to drive cancer progression. Cancer Res. 71, 2417-2422.

Nucera, C., Nehs, M. A., Nagarkatti, S. S., Sadow, P. M., Mekel, M., Fischer, A. H., Lin, P. S., Bollag, G. E., Lawler, J., Hodin, R. A., and Parangi, S. (2011b). Targeting BRAFV600E with PLX4720 displays potent antimigratory and antiinvasive activity in preclinical models of human thyroid cancer. Oncologist 16, 296-309.

Nucera, C., Porrello, A., Antonello, Z. A., Mekel, M., Nehs, M. A., Giordano, T. J., Gerald, D., Benjamin, L. E., Priolo, C., Puxeddu, E., Finn, S., Jarzab, B., Hodin, R. A., Pontecorvi, A., Nose, V., Lawler, J., and Parangi, S. (2010). B-Raf(V600E) and thrombospondin-1 promote thyroid 
cancer progression. Proc. Natl. Acad. Sci. U.S.A. 107, 10649-10654.

Ott, P. A., Hamilton, A., Min, C., Safarzadeh-Amiri, S., Goldberg, L., Yoon, J., Yee, H., Buckley, M., Christos, P. J., Wright, J. J., Polsky, D., Osman, I., Liebes, L., and Pavlick, A. C. (2010). A phase II trial of sorafenib in metastatic melanoma with tissue correlates. PLOS ONE 5, e15588. doi:10.1371/journal.pone.0015588

Pacini, F., Schlumberger, M., Dralle, H., Elisei, R., Smit, J. W., and Wiersinga, W. (2006). European consensus for the management of patients with differentiated thyroid carcinoma of the follicular epithelium. Eur. J. Endocrinol. 154, 787-803.

Papini, E., Guglielmi, R., Bianchini, A., Crescenzi, A., Taccogna, S., Nardi, F., Panunzi, C., Rinaldi, R., Toscano, V., and Pacella, C. M. (2002). Risk of malignancy in nonpalpable thyroid nodules: predictive value of ultrasound and color-Doppler features. J. Clin. Endocrinol. Metab. 87, 1941-1946.

Papini, E., Guglielmi, R., Hosseim, G., Misischi, I., Graziano, F., Chianelli, M., Crescenzi, A., Bianchini, A., Valle, D., and Bizzarri, G. (2011). Ultrasound-guided laser ablation of incidental papillary thyroid microcarcinoma: a potential therapeutic approach in patients at surgical risk. Thyroid 21, 917-920.

Pazaitou-Panayiotou, K., Capezzone, M., and Pacini, F. (2007). Clinical features and therapeutic implication of papillary thyroid microcarcinoma. Thyroid 17, 1085-1092.

Pelizzo, M. R., Bernante, P., Toniato, A., and Fassina, A. (1997). Frequency of thyroid carcinoma in a recent series of 539 consecutive thyroidectomies for multinodular goiter. Tumori 83 , 653-655.

Pelizzo, M. R., Boschin, I. M., Toniato, A., Pagetta, C., Piotto, A., Bernante, P., Casara, D., Pennelli, G., and Rubello, D. (2004). Natural history, diagnosis, treatment and outcome of papillary thyroid microcarcinoma (PTMC): a mono-institutional 12year experience. Nucl. Med. Commun. 25, 547-552.
Pellegriti, G., Scollo, C., Lumera, G., Regalbuto, C., Vigneri, R., and Belfiore, A. (2004). Clinical behavior and outcome of papillary thyroid cancers smaller than $1.5 \mathrm{~cm}$ in diameter: study of 299 cases. J. Clin. Endocrinol. Metab. 89, 3713-3720.

Ringel, M. D. (2011). Metastatic dormancy and progression in thyroid cancer: targeting cells in the metastatic frontier. Thyroid 21, 487-492.

Rodriguez, J. M., Moreno, A., Parrilla, P., Sola, J., Soria, T., Tebar, F. J. and Aranda, F. (1997). Papillary thyroid microcarcinoma: clinical study and prognosis. Eur. J. Surg. 163, 255-259.

Roti, E., Rossi, R., Trasforini, G., Bertelli, F., Ambrosio, M. R., Busutti, L., Pearce, E. N., Braverman, L. E., and Degli Uberti, E. C. (2006). Clini$\mathrm{cal}$ and histological characteristics of papillary thyroid microcarcinoma: results of a retrospective study in 243 patients. J. Clin. Endocrinol. Metab. 91, 2171-2178.

Sakorafas, G. H., Stafyla, V., Kolettis, T., Tolumis, G., Kassaras, G., and Peros, G. (2007). Microscopic papillary thyroid cancer as an incidental finding in patients treated surgically for presumably benign thyroid disease. J. Postgrad. Med. 53, 23-26.

Salerno, P., De Falco, V., Tamburrino, A., Nappi, T. C., Vecchio, G., Schweppe, R. E., Bollag, G., Santoro, M., and Salvatore, G. (2010). Cytostatic activity of adenosine triphosphatecompetitive kinase inhibitors in BRAF mutant thyroid carcinoma cells. J. Clin. Endocrinol. Metab. 95, 450-455.

Schwartz, R. W., Kenady, D. E., Bensema, M., McGrath, P. C., and Flueck, J. (1989). Medullary thyroid cancer and Graves' disease. Surgery 105, 804-807.

Sedliarou, I., Saenko, V., Lantsov, D., Rogounovitch, T., Namba, H., Abrosimov, A., Lushnikov, E., Kumagai, A., Nakashima, M., Meirmanov, S., Mine, M., Hayashi, T., and Yamashita, S. (2004). The BRAFT1796A transversion is a prevalent mutational event in human thyroid microcarcinoma. Int. J. Oncol. 25, 1729-1735.
Shaha, A. R., Tuttle, R. M., and Shah, J. P. (2007). Papillary microcarcinoma of the thyroid. J. Surg. Oncol. 95, 532-533.

Shattuck, T. M., Westra, W. H., Ladenson, P. W., and Arnold, A. (2005). Independent clonal origins of distinct tumor foci in multifocal papillary thyroid carcinoma. N. Engl. J. Med. 352, 2406-2412.

Soares, P., and Sobrinho-Simoes, M. (2011). Cancer: small papillary thyroid cancers - is BRAF of prognostic value? Nat. Rev. Endocrinol. 7, 9-10.

Sugitani, I., and Fujimoto, Y. (1999). Symptomatic versus asymptomatic papillary thyroid microcarcinoma: a retrospective analysis of surgical outcome and prognostic factors. Endocr. J. 46, 209-216.

Sugitani, I., Yanagisawa, A., Shimizu, A., Kato, M., and Fujimoto, Y. (1998) Clinicopathologic and immunohistochemical studies of papillary thyroid microcarcinoma presenting with cervical lymphadenopathy. World J. Surg. 22, 731-737.

Tallini, G., Santoro, M., Helie, M., Carlomagno, F., Salvatore, G., Chiappetta, G., Carcangiu, M. L., and Fusco, A. (1998). RET/PTC oncogene activation defines a subset of papillary thyroid carcinomas lacking evidence of progression to poorly differentiated or undifferentiated tumor phenotypes. Clin. Cancer Res. 4, 287-294.

Tsai, J., Lee, J. T., Wang, W., Zhang, J., Cho, H., Mamo, S., Bremer, R., Gillette, S., Kong, J., Haass, N. K., Sproesser, K., Li, L., Smalley, K. S., Fong, D., Zhu, Y. L., Marimuthu, A., Nguyen, H., Lam, B., Liu, J., Cheung, I., Rice, J., Suzuki, Y., Luu, C., Settachatgul, C., Shellooe, R., Cantwell, J., Kim, S. H., Schlessinger, J., Zhang, K. Y., West, B. L., Powell, B., Habets, G., Zhang, C., Ibrahim, P. N., Hirth, P., Artis, D. R., Herlyn, M., and Bollag, G. (2008). Discovery of a selective inhibitor of oncogenic B-Raf kinase with potent antimelanoma activity. Proc. Natl. Acad. Sci. U.S.A. 105, 3041-3046.

Ugolini, C., Giannini, R., Lupi, C., Salvatore, G., Miccoli, P., Proietti, A., Elisei, R., Santoro, M., and Basolo, F.
(2007). Presence of BRAF V600E in very early stages of papillary thyroid carcinoma. Thyroid 17, 381-388.

Xing, M. (2007). BRAF mutation in papillary thyroid cancer: pathogenic role, molecular bases, and clinical implications. Endocr. Rev. 28, $742-762$.

Xing, M. (2009). BRAF mutation in papillary thyroid microcarcinoma: the promise of better risk management. Ann. Surg. Oncol. 16, 801-803. Yamashita, H., Noguchi, S., Murakami, N., Toda, M., Uchino, S., Watanabe, S., and Kawamoto, H. (1999). Extracapsular invasion of lymph node metastasis. A good indicator of disease recurrence and poor prognosis in patients with thyroid microcarcinoma. Cancer 86, 842-849.

Yun, M., Noh, T. W., Cho, A., Choi, Y. J., Hong, S. W., Park, C. S., Lee, J. D., and Kim, C. K. (2010). Visually discernible $[18 \mathrm{~F}]$ fluorodeoxyglucose uptake in papillary thyroid microcarcinoma: a potential new risk factor. J. Clin. Endocrinol. Metab. 95, 3182-3188.

Conflict of Interest Statement: The authors declare that the research was conducted in the absence of any commercial or financial relationships that could be construed as a potential conflict of interest.

Received: 14 December 2011; accepted: 11 February 2012; published online: 27 February 2012.

Citation: Nucera $C$ and Pontecorvi A (2012) Clinical outcome, role of $B R A F^{V 600 E}$, and molecular pathways in papillary thyroid microcarcinoma: is it an indolent cancer or an early stage of papillary thyroid cancer? Front. Endocrin. 3:33. doi: 10.3389/fendo.2012.00033 This article was submitted to Frontiers in Cancer Endocrinology, a specialty of Frontiers in Endocrinology.

Copyright (c) 2012 Nucera and Pontecorvi. This is an open-access article distributed under the terms of the Creative Commons Attribution Non Commercial License, which permits noncommercial use, distribution, and reproduction in other forums, provided the original authors and source are credited. 